\title{
Professor Alain B. Rossier, MD, Immediate Past President and Medallist of the International Medical Society of Paraplegia: A Profile
}

Professor Alain B. Rossier, the very distinguished Past President of the International Medical Society of Paraplegia was elected Medallist of the Society at its Annual Scientific Meeting in Stoke Mandeville Hospital, UK in 1987.

As determined as he was as a diplomat, Alain Rossier was from 1984 to 1988 an efficacious President of the Society by the breadth of his knowledge on all the aspects of the consequences of a spinal injury. Committed to develop the scientific impact of the International Medical Society of Paraplegia, which he wanted to place amongst the foremost scientific institutions, our fifth President was, above all, intent on helping paraplegics the world over by bringing to the doctors and nurses and allied health workers, and the authorities in charge, the best possible information.

How many times have we not heard him express his concern about countries where the treatment of spinal cord injuries remains rudimentary for lack of material and medical means.

Before he became President, Alain Rossier was, for many of our members, a brilliant researcher oriented towards the study, in minute detail, of the urological problems and complications of the paraplegic patient. Urodynamics was, and remains the favourite theme of his precise lectures, wonderfully illustrated and impregnated by his 4 years of paraplegist formation with Dr Ernest Bors.

Born in Lausanne on 29 November 1930, Alain Rossier studied medicine in Lausanne and in Paris, and was awarded the title of Graduate of the University Medical School of Lausanne in 1957 and the diploma of the Doctorate of the University Medical Faculty of Lausanne in 1958 at the age of 27. But he had already become acquaintanted with the treatment and the rehabilitation of paraplegia, one year before, by taking a course at the 'Centre de Rééducation de Fointainebleau' near Paris, directed by Dr Marc Maury, well known to the members of IMSP.

From Fontainebleau to Aylesbury, there was only the Channel to cross, and Alain Rossier crossed it in 1959. It was at this time, at Stoke Mandeville, in those old buildings which became the National Spinal Injuries Centre, thanks to Ludwig Guttmann and his colleagues, L .S. Michaelis, J. Melzak and later Jack Walsh, that I became acquainted with Alain Rossier and another individual who spoke a dialect which I understood to be French and who turned out to be Paul Dolfuss. This language in particular immediately favoured our contacts which became closer with the years of parallel evolution in our formation of paraplegists, even if it was not quite contemporaneous.

Events passed through Rome, on the occasion of the IX International Stoke Mandeville Games, the 1st Paralympics in September 1960. Alain was there to 


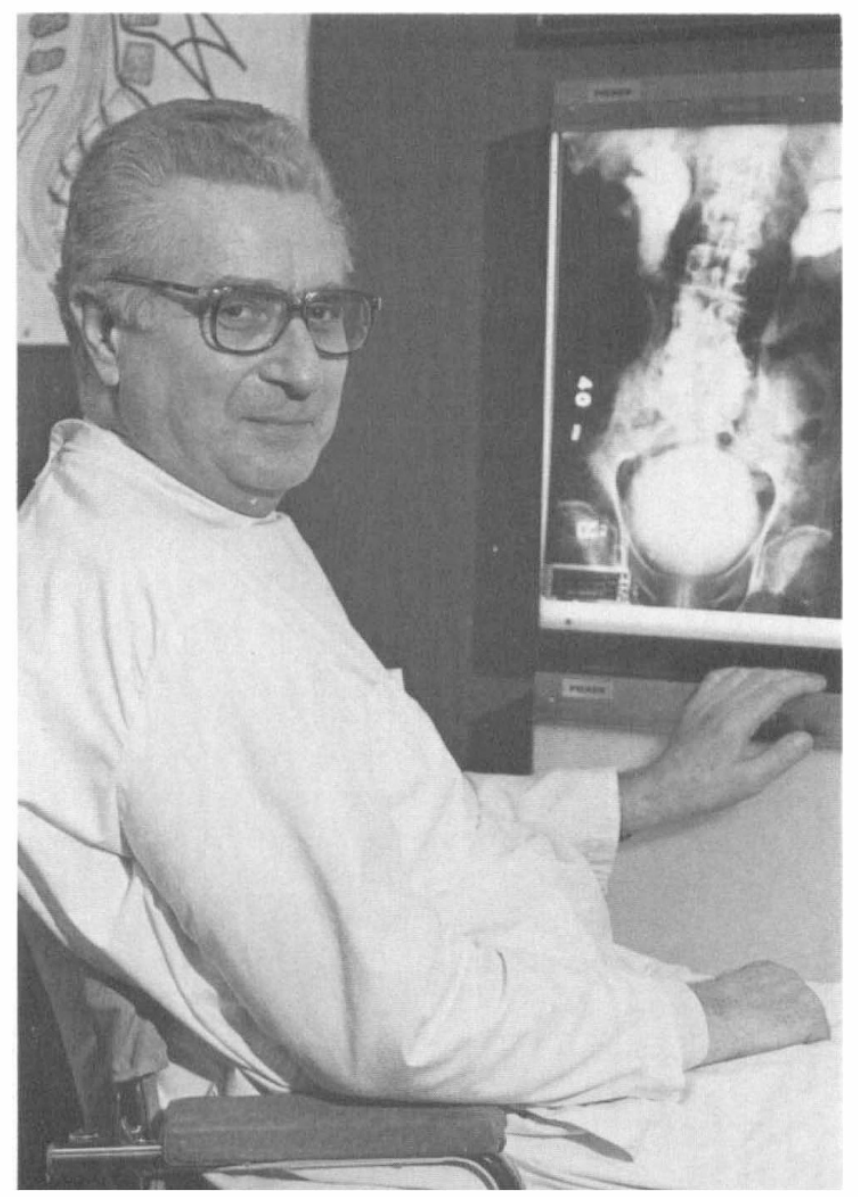

present to the Annual Scientific Meeting of the IMSP, his first paper and at the same time his first lecture on a urological problem 'Discussion of a case of hydronephrosis with ipsilateral lithiasis and pelvic controlateral ectopy'.

For its first gathering outside its British premises, the Rome Scientific Meeting was a great success of which Sir Ludwig and Jack Walsh were justifiably proud.

From all the images which have stuck in my memory, one stands out but it is neither scientific nor sportive: that of a white limousine, an open Mercedes steered by a young woman, taking a tender and jealous care of Alain. I had just met for the first time this girl from the North, Birte, the faithful spouse, who sometimes grumbling, but always with an understanding and smiling philosophy had to adapt herself to the hectic life of her Alain.

In the meantime, Alain Rossier had already taken courses of different durations in some specialised units: 'Centre de Traitement des Séquelles Poliomyélitiques' at Garches, France, the 'Balgrist University Orthopaedic Clinic' of Zürich, Switzerland, the 'Urological Service of University Hospital' also at Zürich.

Alain had already then proven his interest for the whole range of the problems 
provoked by a medullary injury. His first three articles in the Swiss medical press are revealing: 'The Medico Social Problems of Paraplegics'; 'The Problems of Urgency and Primary Care in Traumatic Paraplegia'; 'Disabled Sport and Paraplegics'.

In Rome, upon leaving us at the end of September 1960, Alain had discussed with me with a sparkle in his eyes and the ravenous look which we all recognise in him when he is captivated by some subject, of the stay he was contemplating at Long Beach, California Veterans Adminstration Hospital, more precisely the Spinal Cord Injury Service, directed by Dr Bors.

The Swiss Academy of Medical Science had elected him for a probation course he took in 1961-62 and another probation course in 1963-64 also with the aid of the American Swiss Foundation for Scientific Exchange. Between these two courses, of which Alain Rossier often recalls the enriching value, he had made a prolonged visit to Dr Howard Rusk at the Institute of Physical Medicine and Rehabilitation of New York under the aegis of the World Rehabilitation Fund. Afterwards he came back to his native Swiss Canton where we find him at the Medical Service of Professor P. H. Rossier of the University Hospital of Zürich.

In the visitors' book (visitors and students alike) of the Department of Physical Medicine and Rehabilitation of the Albert Einstein College of Medicine of New York, Bronx, directed by Professor A. Abramson, we find Alain Rossier's name in the year 1963.

At that period, visitors to the United States who were interested in paraplegia, had to follow obligatory stages for their schooling as 'paraplegists' or specialists in Rehabilitation: New York (N.Y. University and Yeshiva University), Los Angeles, (Los Rachos Amigos), Long Beach (Veterans Administration Hospital). Later, these other Universities would make themselves known in Europe.

After his second course in the United States, Alain Rossier came back to Europe, to Switzerland where he was nominated on 1 October 1964, Head of the quite new service of Paraplegia, created by his recommendation at the University Hospital of Beau-Séjour in Geneva. He also became Service Head Assistant of the Institute of Physical Medicine and Rehabilitation and consultant for spinal cord injuries at the Neurosurgical and Urological Services of the same University of Geneva.

In the course of the year 1972, Alain Rossier received an exceptional proposition which tallied most appropriately with his scientific reputation, his experience in the field of paraplegia but also with his organisational capacities and his methodical and systematic character. He first told his wife secretly and then his innermost circle of friends in which I was most flattered to find myself. After some thoughts and discussions, his dynamic temperament took the lead and on 1 April 1973, Alain Rossier became Head of the Spinal Cord Injury Service of the Veterans Administration Hospital, West-Roxbury, Boston, Massachusetts. This time, wife, dog, car and furniture crossed the Atlantic. Bye - bye Alain, but we shall often meet you again at our scientific meetings, more particularly in Phoenix, Arizona in 1973, but most specially at an unforgettable gathering of the GENULF (Study Group of French-Speaking Neuro-Urologists) in Boston on 10 and 11 May 1979. We were all most impressed by the organisation and the equipment of this new Paraplegia Unit, which certainly 
bore the stamp of Alain Rossier's stubbornness (a quality which we should not overlook).

The American episode (should it be the last?) ended on 1 July 1984 with enormous regrets and hopes, and not without Alain Rossier's appointment as lecturer on Spinal Cord Rehabilitation, Department of Orthopaedic Surgery (Children's Hospital at Boston) at the Braintree Hospital Massachussets and at the Massachussets Rehabilitation Hospital, Boston, as well as Member of the Associate Staff at the New England Medical Center Tufts University, also in Boston.

The return to Europe, to Switzerland, to Geneva, meant a more relaxed life without managerial and administrative responsibilities, without professional obligations and imposed timings, and the resulting possibility to do as one pleases, when it pleases.

Alain Rossier wanted some rest; Birte Rossier didn't expect he would take some, and she was right!

The Presidency of the IMSP, as absorbing as it could be, was only a leisurely occupation for a man of Alain Rossier's creative urge. He was charged with the study, the realisation and the management of the Paraplegic Unit, University Orthopaedic Clinic Balgrist at Zürich (some 30 years after making his first appearance there as student on a probation course).

Titular of several Awards, Consultant at the Neurological Service, Sion Hospital Switzerland, Private Docent at the Faculty of Medicine at the Geneva University since 1970 , lecturer for the problems of trauma of the spinal cord at the University in Boston, Adjunct Professor of Spinal Cord Rehabilitation, Department of Orthopaedic Surgery Tufts University, Boston, USA, Alain Rossier was in September 1987, appointed Professor of Paraplegiology at the University Medical School, Zürich, Switzerland.

I should go on to mention several other titles, his collaboration to a dozen scientific magazines, his affiliation to more than twenty scientific societies in Europe and in the United States, his studies for the development of new units for the treatment of paraplegics, especially in Africa and Asia, but more than all that, the International Medical Society of Paraplegia is marked by the personality of a man who is devoted to the improvement of the treatment of paraplegics and tetraplegics the world over, in the steps of Sir Ludwig Guttmann.

My dear President, The IMSP and all its members express their deep gratitude, you are a most worthy medallist.

Professor Hre Albert Tricot Emeritus Member and Ex President 